Ensino, Saúde e Ambiente - V7 (3), p. 30-49, Dez. 2014

\title{
LEVANTAMENTO E CLASSIFICAÇÃO DAS ANALOGIAS PRESENTES EM LIVROS DIDÁTICOS DE BIOLOGIA DO ENSINO MÉDIO, COM ENFOQUE NO TEMA GENÉTICA
}

\author{
SURVEY AND CLASSIFICATION OF ANALOGIES PRESENT ON \\ TEXTBOOKS BIOLOGY OF SCHOOL, WITH FOCUS ON TOPIC GENETICS
}

\author{
Lucicléia Kalamar $^{1}$ e Camila Juraszeck Machado ${ }^{2}$ \\ Universidade Estadual do Paraná - UNESPAR \\ Campus de União da Vitória- Paraná
}

\section{RESUMO}

Analogias são ferramentas utilizadas para facilitar a aprendizagem, estas são frequentes nas aulas de biologia, pois fazem conexão entre duas situações com padrão de relação comum entre ambas. As analogias devem ser usadas quando o conceito alvo é difícil de ser explicado ou compreendido, precisam ser simples e com linguagem clara, caso contrario, podem dificultar o processo de ensino-aprendizagem. $\mathrm{O}$ objetivo deste trabalho foi investigar as analogias presentes no conteúdo de Genética, em Livros Didáticos de Biologia do Ensino Médio aprovados pelo Plano Nacional do Livro Didático (PNLD) no ano de 2012. O presente tema foi escolhido por ser considerado de difícil compreensão por grande parte dos alunos. Para isso, foi realizada a leitura e análise dos capítulos referentes ao tema, e identificadas 42 analogias nas 8 obras analisadas, as quais foram quantificadas e classificadas. Verificamos que certos autores adotam mais esse recurso didático quando comparado a outros autores. Observamos ainda que as analogias do tipo simples são as que mais se destacam nos livros didáticos.

Palavras Chave: Modelo mental, Recursos didáticos, Ensino-aprendizagem, Aulas de Biologia, Ensino de Genética.

\begin{abstract}
Analogies are tools used to facilitate learning, these are frequent in biology classes because it make connection between two situations with standard common relationship between them. Analogies should be used when the target concept is hard to explain or understand, need to be simple and, otherwise clear language, can hinder the process of teaching and learning. The objective of this study was to investigate the analogies present in the contents of Genetics in Biology Textbooks of Secondary Education approved the National Plan for Textbooks (PNLD) in 2012. This theme was chosen because it is considered difficult to understand by most students. For this, the reading and analysis of chapters on the topic was conducted, and identified 42 articles analyzed analogies in 8 , which were quantified and classified. We found that certain authors have adopted this more didactic resource when compared to other authors. We also observed that the analogies of simple type are the most distinctive in textbooks.
\end{abstract}

Key words: Mental model, Learning resources, Learning, Teaching lessons of Biology, School of Genetics. 


\section{INTRODUÇÃO}

Para uma aprendizagem efetiva o indivíduo deve atribuir significado ao conhecimento ensinado. Para isso, o aprendiz precisa encontrar ou criar conexões entre a nova informação e o conhecimento já existente, um dos modos de efetivar esse processo é por meio do uso de analogias (ZAMBON; TERRAZZAN, 2013).

O uso de analogias é muito frequente na linguagem cotidiana, é uma forma dinâmica de raciocínio que está presente no pensamento criador (OLIVEIRA, 2012). É difícil passarmos um dia sem fazer uso delas, pois utilizamos analogias para explicar algo para alguém, sendo comum usarmos expressões do tipo: "Parece com...", "É como se fosse...", "Imagine que...". Em todos estes casos há sempre a ideia de uma comparação, ou seja, de uma analogia (TERRAZZAN et al., 2005).

Encontramos atualmente vários conceitos para analogia, entretanto a definição mais comum é a semelhança entre os conceitos no momento de comparar duas propriedades distintas, porem parecidas emprestando ideias conhecidas ou mesmos criando para obter a compreensão desejada (SANTOS; TERÁN; FORSBERGUE, 2011). Para Fabião e Duarte (2005), as analogias possuem várias definições, porem são reconhecidas como um modelo para compreender algo novo de difícil compreensão. Para Zambon; Piccini e Terrazan (2009), às analogias fazem comparações entre assuntos diferentes, mas mantém entre elas relações de semelhança. No processo de aprendizagem, as analogias provocam o interesse dos alunos porque são maneiras de se usar um estilo menos rígido e mais expressivo para o entendimento dos conceitos (DUARTE, 2005).

Muitas vezes a linguagem utilizada em sala de aula faz com que os alunos não compreendam o que está sendo ensinado, dificultando o processo de ensinoaprendizagem. Entretanto, para superar este obstáculo, podemos utilizar nas aulas exemplos práticos e de fácil assimilação para a explicação da linguagem científica, uma vez que a maioria dos alunos não domina a linguagem técnica necessária ao seu pleno entendimento (MAESTRELLI; FERRARI, 2006).

A maioria dos conceitos ensinados requer uma alta compreensão por parte dos alunos fazendo com que estes sejam capazes de imaginar e modelar, mas sabendo que tal processo não é simples, o professor sente, em algumas situações, a necessidade de utilizar uma situação mais familiar aos alunos. Nesse sentido, as analogias são utilizadas 
como recursos didáticos no ensino, pois elas apresentam similaridades entre dois conceitos diferentes, sendo um familiar ao aluno denominado "análogo", e outro, não familiar chamado "alvo" (BOZELLI; NARDI, 2009).

Utilizar analogias tem certa importância, isso se deve ao fato de explicar conceitos científicos envolvendo tanto entender o conteúdo quanto ser capaz de comunicar esse conteúdo de maneira efetiva. O uso de analogias é crucial no conhecimento, pois vem se destacando na comunicação entre professores e alunos em sala de aula (BOZELLI; NARDI, 2009). Elas não resultam de uma mera necessidade de uma linguagem mais apropriada para a comunicação, mas sim, de um elemento necessário do conhecimento cientifico (HOFMAN, 2012), pois realizam um mapeamento de uma estrutura conceitual a uma similaridade (SANTOS; NUNES, 2013).

As analogias são descritas como importantes ferramentas no ensino de ciências e biologia, pois fazem conexão entre duas situações com padrão de relação comum entre ambas. Junior (2009) aponta que esse termo pode ser aplicado em qualquer situação para introduzir conceitos novos, ou ainda estimular a sua criatividade, podendo construir suas próprias analogias. Já que elaborar analogias é uma das habilidades do ser humano (MARTINS; BARREIRA, 2009).

Para entender melhor esse conceito Maestrelli e Ferrari (2006), fazem uma analogia entre uma pia de cozinha com duas torneiras e o organismo do menino Lorenzo utilizado no filme "O óleo de Lorenzo": Onde a pia seria o organismo de Lorenzo, por uma das torneiras entram no organismo os ácidos graxos provenientes da dieta, pela outra entram os ácidos graxos provenientes da biossíntese. O ralo da pia é representado pela enzima que degrada essas gorduras, que se encontra ausente na pessoa com ALD. Também são utilizados clipes de papel para representar os mecanismos de biossíntese e degradação das cadeias de ácidos graxos. Em outra analogia descrita por Pedroso e Amorim (2009), dois prédios vizinhos que possuem a mesma planta arquitetônica foram projetados em comparação a um par de cromossomos homólogos para facilitar o entendimento do conceito.

Maestrelli e Ferrari (2006) destacam que as analogias podem ser úteis por trazer um problema desconhecido para uma situação cotidiana, o que facilita o raciocínio. Para Giraldi (2005), sem duvidas as analogias auxiliam no ensino, pois aproximam a linguagem comum da linguagem cientifica. 
Entretanto uma das preocupações de alguns autores é a de que muitas vezes o análogo utilizado pelo professor ou pelo livro didático não seja conhecido por todos os alunos (ZAMBON; TERRAZZAN, 2013). Isso pode ser um perigo, fazendo com que o aluno não entenda o papel dessa ferramenta no ensino (SILVA, 2007). Cabe então ao professor, antecipar quaisquer dificuldades que possam prejudicar o emprego de analogias no ensino, acrescentando os elementos necessários para facilita-las (FIGUEROA; NAGEM; CARVALHO, 2004), pois as analogias apenas contribuem para a aprendizagem, quando obedecem a critérios na sua utilização (HOFFMANN; SCHEID, 2006). Embora alguns autores considerem que a solução é não usar analogias, esse fato se mostra irreal, uma vez que professores, autores de livros didáticos, e todos os seres humanos, pensam analogicamente, e utilizam analogias em suas explicações (HOFFMAM; SHEID, 2007).

As analogias estão presentes nos livros didáticos de biologia, pois aproximam um assunto complexo de ser compreendido, com a realidade do aluno, e essa aproximação contribui para o melhor entendimento dos conceitos (SOARES; FERRAZ; JUSTINA, 2008). Apesar dos diversos recursos que estão disponíveis atualmente, o livro didático ainda é o mais utilizado em sala de aula. De acordo com Junior (2009), os livros didáticos são importantes mecanismos de conceitos e em algumas ocasiões podem ser a única alternativa para a qual o professor recorre. Para Neto e Fracalanza (2003), o livro didático é utilizado tanto por alunos como por professores como apoio às atividades, seja em sala de aula ou em atividades extraescolares.

Sendo assim, o objetivo deste estudo foi fazer um levantamento e análise das analogias presentes no conteúdo de Genética de livros didáticos de biologia aprovados pelo plano nacional do livro didático (PNLD) 2012. O ensino de genética é desafiador, e tem causado impacto no mundo contemporâneo devido seu envolvimento cada vez maior em nosso cotidiano (TEMP, 2011). Segundo Goldbach e El-Hani (2008), a genética possui muitas dificuldades no que diz respeito à compreensão de seus elementos. Fatalmente, talvez isso ocorra devido à forma tradicional de ensino. Simplificar a maneira como esse tema vem sendo tratado, talvez seja uma possível alternativa à construção do conhecimento (MELO; CARMO, 2009). Para Agamme (2010) a genética é um dos conteúdos que são considerados mais difíceis da biologia, pronunciada tanto por alunos, quanto por professores de ciências e biologia. Uma alternativa para o ensino de genética é o uso de apresentações analógicas que através de 
semelhanças e diferenças estabelecidas entre um domínio conhecido ou familiar auxiliam na construção de conceitos pelos alunos, a partir dos seus conhecimentos prévios (PEDROSO; AMORIM, 2009). É importante lembrar que as analogias contribuem para a aprendizagem quando o conteúdo é difícil de ser compreendido (JUSTI; MENDONÇA, 2003).

\section{METODOLOGIA}

Foi consultado o Guia do PNLD (2012), onde constam todas as coleções de livros didáticos de biologia aprovados para a escolha dos livros pelos professores nos colégios, estes foram utilizados nos anos de 2012, 2013 e 2014. A coleta de dados foi realizada nas oito coleções aprovadas (Tabela 1), sendo que foram analisados somente textos, (não incluindo exercícios e questões de vestibulares) dos capítulos que se referem ao tema Genética.

Tabela 1- Dados referentes aos oito livros analisados.

\begin{tabular}{|c|c|c|c|}
\hline AUTORES & ANO & $\begin{array}{l}\text { EDITORA } \\
\text { E } \\
\text { VOLUME }\end{array}$ & CAPÍTULOS ANALISADOS \\
\hline $\begin{array}{l}\text { Amabis } \\
\text { Martho. }\end{array}$ & 2010 & $\begin{array}{l}\text { Moderna } \\
\text { Vol. } 1\end{array}$ & $\begin{array}{l}\text { Cap. 1: A descoberta da segregação dos } \\
\text { genes; Cap. 2: Relação entre genótipo e } \\
\text { fenótipo; Cap. 3: Genes com segregação } \\
\text { independente; Cap. 4: Genética relacionada ao } \\
\text { sexo e ligação gênica; Cap. 5: Aplicações do } \\
\text { conhecimento genético. }\end{array}$ \\
\hline $\begin{array}{l}\text { Pezzi; } \\
\text { Gowdak } \\
\text { Mattos }\end{array}$ & 2010 & $\begin{array}{l}\text { FTD } \\
\text { Vol.1 }\end{array}$ & $\begin{array}{l}\text { Cap. 1: Hereditariedade e Mendelismo; Cap. } \\
\text { 2: Variação na distribuição dos descendentes; } \\
\text { Cap. 3: Polialelismo ou alelos múltiplos; Cap. } \\
\text { 4: Interação Gênica; Cap. 5: Genética do sexo. }\end{array}$ \\
\hline $\begin{array}{l}\text { Lopes } \\
\text { Rosso }\end{array}$ & 2010 & $\begin{array}{l}\text { Saraiva } \\
\text { Vol.2 }\end{array}$ & $\begin{array}{l}\text { Cap.7: A genética e os genes; Cap. 8: A } \\
\text { herança de uma característica; Cap. 9: A } \\
\text { herança simultânea de duas ou mais } \\
\text { características; Cap. 10: Outros mecanismos } \\
\text { de herança; Cap. 11: Biotecnologia. }\end{array}$ \\
\hline $\begin{array}{l}\text { Mendonça e } \\
\text { Laurence }\end{array}$ & 2010 & $\begin{array}{l}\text { Nova } \\
\text { Geração } \\
\text { Vol.1 }\end{array}$ & $\begin{array}{l}\text { Cap. 6: Genética: Primeira Lei de Mendel; } \\
\text { Cap. 7: Polialelia; Cap. 8: Segunda Lei de } \\
\text { Mendel; Cap. 9: Genética pós-Mendel; Cap. } \\
\text { 10: Biologia molecular do gene: Síntese }\end{array}$ \\
\hline
\end{tabular}




\begin{tabular}{|c|c|c|c|}
\hline & & & proteica e engenharia genética. \\
\hline Bizzo & 2010 & $\begin{array}{l}\text { Ática } \\
\text { Vol.1 }\end{array}$ & $\begin{array}{l}\text { Cap. 4: As bases da genética; Cap. 5: } \\
\text { Expansão da genética. }\end{array}$ \\
\hline $\begin{array}{l}\text { Linhares e } \\
\text { Gewandsz- } \\
\text { najder }\end{array}$ & 2010 & $\begin{array}{l}\text { Ática } \\
\text { Vol.1 }\end{array}$ & $\begin{array}{l}\text { Cap. 1: Primeira Lei de Mendel; Cap. 2: } \\
\text { Probabilidade e Genética molecular; Cap. 3: } \\
\text { Segunda Lei de Mendel; Cap. 4: Polialelia e } \\
\text { Grupos sanguíneos; Cap. 5: Interação Gênica; } \\
\text { Cap. 6: Ligação Gênica; Cap. 7: Sexo e } \\
\text { Herança Genética; Cap. } 8 \text { A Tecnologia do } \\
\text { DNA. }\end{array}$ \\
\hline $\begin{array}{l}\text { César; Sezar } \\
\text { e Caldini }\end{array}$ & 2010 & $\begin{array}{l}\text { Saraiva } \\
\text { Vol.1 }\end{array}$ & $\begin{array}{l}\text { Cap. 5: Os trabalhos de Mendel: a primeira } \\
\text { lei; Cap. 6: A primeira lei de Mendel e a } \\
\text { espécie humana; Cap. 7: Genética e } \\
\text { probabilidades; Cap. 8: Os alelos múltiplos; } \\
\text { Cap. 9: cromossomos sexuais e a herança de } \\
\text { seus genes; Cap. 10: A segunda Lei de } \\
\text { Mendel; Cap. 11: A ligação gênica (linkage); } \\
\text { Cap. 12: Interação Gênica; Cap. 13: } \\
\text { Anomalias genéticas na espécie humana; Cap. } \\
\text { 14: Biotecnologia. }\end{array}$ \\
\hline $\begin{array}{l}\text { Santos; } \\
\text { Aguilar } \\
\text { Oliveira }\end{array}$ & 2010 & $\begin{array}{l}\text { SM } \\
\text { Vol.1 }\end{array}$ & $\begin{array}{l}\text { Cap. 1: Primeiras ideias sobre genética; Cap. } \\
\text { 2: Gregor Mendel e a genética; Cap. 3: } \\
\text { Métodos utilizados em genética mendeliana; } \\
\text { Cap. 4: Variações do mono-hibridismo; Cap. } \\
\text { 5: Segunda lei de Mendel; Cap. 6: Genes } \\
\text { ligados, mapas cromossômicos e anomalias } \\
\text { genéticas; Cap. 7: Determinação do sexo e } \\
\text { influência na herança; Cap. 8: biotecnologia. }\end{array}$ \\
\hline
\end{tabular}

Para a contagem e classificação das analogias foi preenchida uma ficha padronizada para cada livro, totalizando 8 fichas (Tabela 02) para posterior análise dos dados.

Tabela 02: Exemplo de ficha padronizada preenchida para cada livro analisado.

(Continua)

Ficha de Avaliação para análise de Analogias em livros didáticos referente ao tema Genética

\section{Título do Livro:}

\section{Autores:}

3 Ano, Volume, Edição e Editora: 
4 Capítulos do Livro que Foram analisados:

5 Numero de Analogias encontradas em cada Capítulo:

6 Total de analogias encontradas:

7 Descrição das Analogias encontradas

\begin{tabular}{l|l|l|l}
\hline Analogias & $\begin{array}{l}\mathbf{N}^{\circ} \text { de vezes } \\
\text { que foi } \\
\text { citada }\end{array}$ & Página & $\begin{array}{l}\text { Classificação das } \\
\text { analogias }\end{array}$ \\
\hline
\end{tabular}

Cada analogia foi classificada conforme as Tabelas 3, 4, 5 e 6 (FERRAZ; TERRAZZAN, 2001; NAGEM et al., 2003; THIELE; TREAGUST, 1992; GONZÁLEZ, 2002 apud RIGOLON, 2006). Uma mesma analogia pode se encaixar em mais de uma classificação, sendo assim, as classificações das analogias podem se sobrepor nos resultados.

Tabela 3- Classificação das analogias pelo nível de organização.

(Continua)

\begin{tabular}{|c|c|}
\hline ANALOGIA & EXEMPLO \\
\hline Simples & $\begin{array}{l}\text { É o símile. Não fazem o mapeamento dos atributos entre o } \\
\text { domínio alvo e o análogo. É quase uma metáfora. Ex.: O coração } \\
\text { é como uma bomba. }\end{array}$ \\
\hline De Limite & $\begin{array}{l}\text { Introduz o domínio alvo e logo indica onde o análogo é diferente. } \\
\text { Poderia ser chamada de contra-analogia. Ex.: As artérias não } \\
\text { podem ser rígidas como um cano de ferro. }\end{array}$ \\
\hline Enriquecida & $\begin{array}{l}\text { É a que faz o mapeamento explícito de algum atributo entre os } \\
\text { domínios alvo e análogo. Ex.: A bile é como um detergente. O } \\
\text { detergente quebra as gotas de gordura da louça em partículas } \\
\text { menores. Da mesma forma, a bile transforma grandes gotas de } \\
\text { gordura em pedaços menores. }\end{array}$ \\
\hline Dupla ou Tripla & $\begin{array}{l}\text { Ocorre quando dois mais conceitos alvos são explicados por } \\
\text { analogia a dois ou mais conceitos análogos. Ex.: O glomérulo de } \\
\text { Malphigi é como se fosse uma bola que funciona como uma } \\
\text { esponja que suga a sujeira. Os vasos eferentes vão se enrolando } \\
\text { como cobras nos túbulos, liberando oxigênio e recebendo gás } \\
\text { carbônico. } \\
\text { (Conclusão) }\end{array}$ \\
\hline Múltipla & $\begin{array}{l}\text { Ocorre quando um conceito alvo é explicado por mais de um } \\
\text { conceito análogo. Ex.: Os capilares passam pelos gânglios, que } \\
\text { funcionam como uma estação de trem. Quando a linfa chega aos } \\
\text { gânglios linfáticos, este funciona como filtro para os }\end{array}$ \\
\hline
\end{tabular}




\begin{tabular}{l|l}
\hline Estendida & microorganismos. \\
\hline $\begin{array}{l}\text { São mais sistemáticas. Nela, vários atributos do alvo são } \\
\text { explicados e fazem correspondências ao análogo. Ela ainda pode } \\
\text { fazer menção dos limites da analogia e até conter mais de um } \\
\text { análogo na comparação. Ex.: Cada aminoácido é como se fosse } \\
\text { uma bolinha de um colar. O colar esticado mostra a estrutura } \\
\text { primária da proteína. A estrutura secundária pode ser em espiral } \\
\text { (enrola-se o colar), como um fio de telefone. No colar, o que } \\
\text { segura as bolinhas é o arame. Nas proteínas, o que segura os } \\
\text { aminoácidos são as ligações peptídicas. }\end{array}$ \\
\hline
\end{tabular}

Fonte: FERRAZ; TERRAZZAN, (2001) apud RIGOLON, (2006).

Tabela 4- Classificação das analogias pela natureza do domínio analógico.

\begin{tabular}{l|l}
\hline ANALOGIA & EXEMPLO \\
\hline Antrópica & $\begin{array}{l}\text { Quando a frase transmite uma idéia de racionalidade, } \\
\text { egocentrismo, atribuindo aos objetos ou fenômenos } \\
\text { característicos dos seres humanos. Ex.: O sistema imunológico } \\
\text { funciona como um exército no corpo. }\end{array}$ \\
\hline Zootrópica & $\begin{array}{l}\text { Quando a frase transmite uma idéia de morfologia ou } \\
\text { comportamento, atribuindo aos animais. Ex.: Ao se cumprimentar } \\
\text { alguém com sudorese nas mãos, tem-se a impressão de estar } \\
\text { pegando num peixe frio molhado. }\end{array}$ \\
\hline Fitotrópica & $\begin{array}{l}\text { Quando a frase transmite uma idéia de morfologia ou } \\
\text { comportamento, atribuindo aos vegetais. Ex.: O fibroadenoma } \\
\text { das mamas parece uma azeitona. }\end{array}$ \\
\hline Fonte: NAGEM et al.,(2003) apud RIGOLON, (2006).
\end{tabular}

Tabela 5- Classificação das analogias pela utilização de desenhos

(Continua)

\begin{tabular}{l|l}
\hline ANALOGIA & EXEMPLO \\
\hline Verbal & $\begin{array}{l}\text { É mostrada apenas verbalmente, na qual os alunos têm de } \\
\text { imaginar a situação analógica. Ex.: Imaginem as órbitas } \\
\text { eletrônicas parecidas com as dos planetas do Sistema Solar. }\end{array}$ \\
\hline $\begin{array}{l}\text { Verbal-ilustrada ou } \\
\text { Verbal-pictórica }\end{array}$ & $\begin{array}{l}\text { É apresentada, além da explicação verbal, com o auxílio de } \\
\text { desenhos no livro, em cartazes ou no quadro-negro ou usando } \\
\text { modelos concretos. Ex.: As hemácias têm a forma de um } \\
\text { damasco seco (e desenha no quadro-negro). }\end{array}$ \\
\hline
\end{tabular}




\begin{tabular}{l|l}
\hline Ilustrada ou & $\begin{array}{l}\text { Só utiliza o desenho, figura, esquema ou modelo para transmitir a } \\
\text { idéia da analogia. É utilizada mais em publicidades. Ex.: Uma } \\
\text { marca de sabão em pó divulga seu produto mostrando uma foto } \\
\text { de um cachorro dálmata sem as manchas pretas, dando a idéia de } \\
\text { que seu produto tiraria até mesmo as manchas naturais do cão. }\end{array}$ \\
\hline
\end{tabular}

Fonte: THIELE; TREAGUST, (1992) apud RIGOLON, (2006).

Tabela 6- Classificação das analogias como objetos de estudo

\begin{tabular}{l|l}
\hline ANALOGIAS & EXEMPLO \\
\hline Múltiplas & $\begin{array}{l}\text { Já descritas. Os estudos dessas analogias costumam comparar os } \\
\text { resultados da aplicação de diferentes analogias para um mesmo } \\
\text { domínio alvo. }\end{array}$ \\
\hline Pictóricas & $\begin{array}{l}\text { Já descritas. A maioria das investigações dessas analogias } \\
\text { pesquisa as figuras dos livros didáticos. }\end{array}$ \\
\hline De ponte & $\begin{array}{l}\text { São as analogias que funcionam como "ganchos cognitivos". } \\
\text { Essas analogias sempre ligam o conceito alvo com algum } \\
\text { fenômeno ou conceito do cotidiano dos alunos. É a preferida das } \\
\text { pesquisas de Psicopedagogia. }\end{array}$ \\
\hline
\end{tabular}

Fonte: GONZÁLEZ, (2002) apud RIGOLON, (2006).

\section{RESULTADOS E DISCUSSÕES}

Das oito obras selecionadas e analisadas, constatou-se um total de 42 analogias para o tema Genética, este numero foi consideravelmente elevado quando comparado ao trabalho de Silva e Martins (2010), onde analisaram analogias e metáforas em toda extensão dos livros didáticos (inclusive em exercícios, tópicos, citações, questões de vestibulares, e outros) de física PNLEM/2007 perfazendo um total de 6 livros, foram encontradas 13 analogias, já no presente estudo constatou-se um total de 42 analogias. Esse elevado número de analogias deve-se ao fato do conteúdo de genética ser um conteúdo complexo, necessitando do uso de mais analogias para sua compreensão. No entanto Terrazzan (2005), manifesta a frequência de distribuições analógicas bastante variadas, pois ao analisar 4 livros didáticos de Biologia em todas as áreas encontrou um total de 414 analogias, registrando seu maior percentual em Citologia, onde dos 4 livros verificados obteve uma média de 44\%, o que é explicado pelo autor por tal assunto englobar assuntos pouco familiares aos alunos, mas adverte que se assim fosse em 
Genética cujo assunto também não é muito familiar, seria de esperar um percentual maior do que os $8,5 \%$ obtidos e considerados extremamente baixos em sua pesquisa.

As analogias são comumente utilizadas tanto em livros didáticos quanto por professores de ciências e biologia. Neste sentido Ferraz e Terrazzan (2002), fizeram observações sobre o uso espontâneo de analogias em três colégios da rede pública e constataram 108 ocorrências em 87 aulas de biologia observadas. Este número significativo de analogias encontradas demonstra que as analogias estão sim presentes no processo de ensino- aprendizagem.

A quantidade de analogias encontradas em cada uma das oito obras analisadas estão representadas no Gráfico 1:

Gráfico 1- Número de analogias encontradas em cada um dos oito livros analisados.

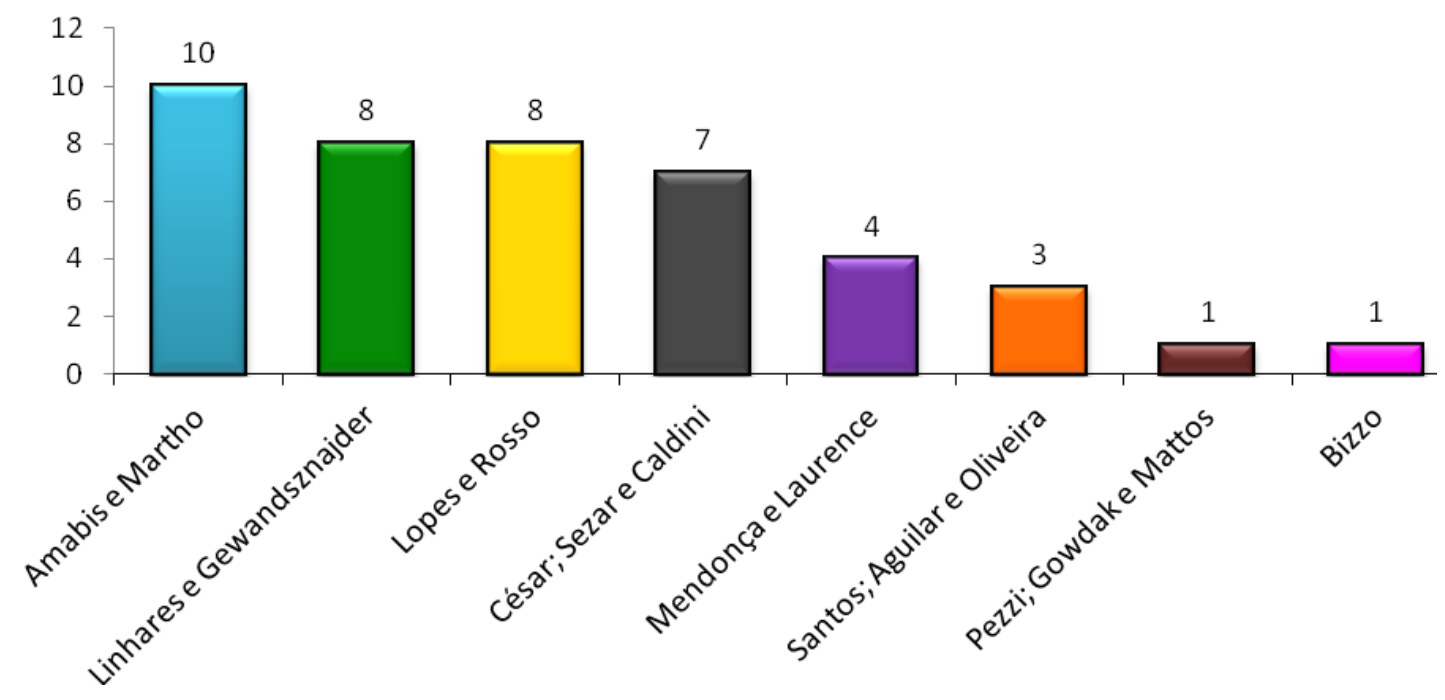

Fonte: KALAMAR, MACHADO, 2014.

Alguns autores fizeram pouco uso de analogias em seus textos o que demonstra que talvez desconheçam seu potencial analógico como modelo de ensino em biologia. Outros utilizaram muitas delas, o que evidencia um estilo próprio de cada autor (JUSTI; MONTEIRO, 2000). Muitas vezes as analogias utilizadas pelos professores em sala de aula não provêm somente dos livros didáticos, mas de outras fontes, do seu cotidiano, do seu dia a dia, de sua criatividade e da sua própria experiência profissional, de modo a facilitar o entendimento dos alunos (FERRAZ; TERRAZZAN, 2002). 
As 42 analogias encontradas nos livros foram classificadas conforme está demonstrado no Gráfico 2:

Gráfico 2- Classificação das analogias de acordo com o nível de organização, de acordo com a natureza do domínio analógico, de acordo com a utilização de desenhos e ainda como objetos de estudo.

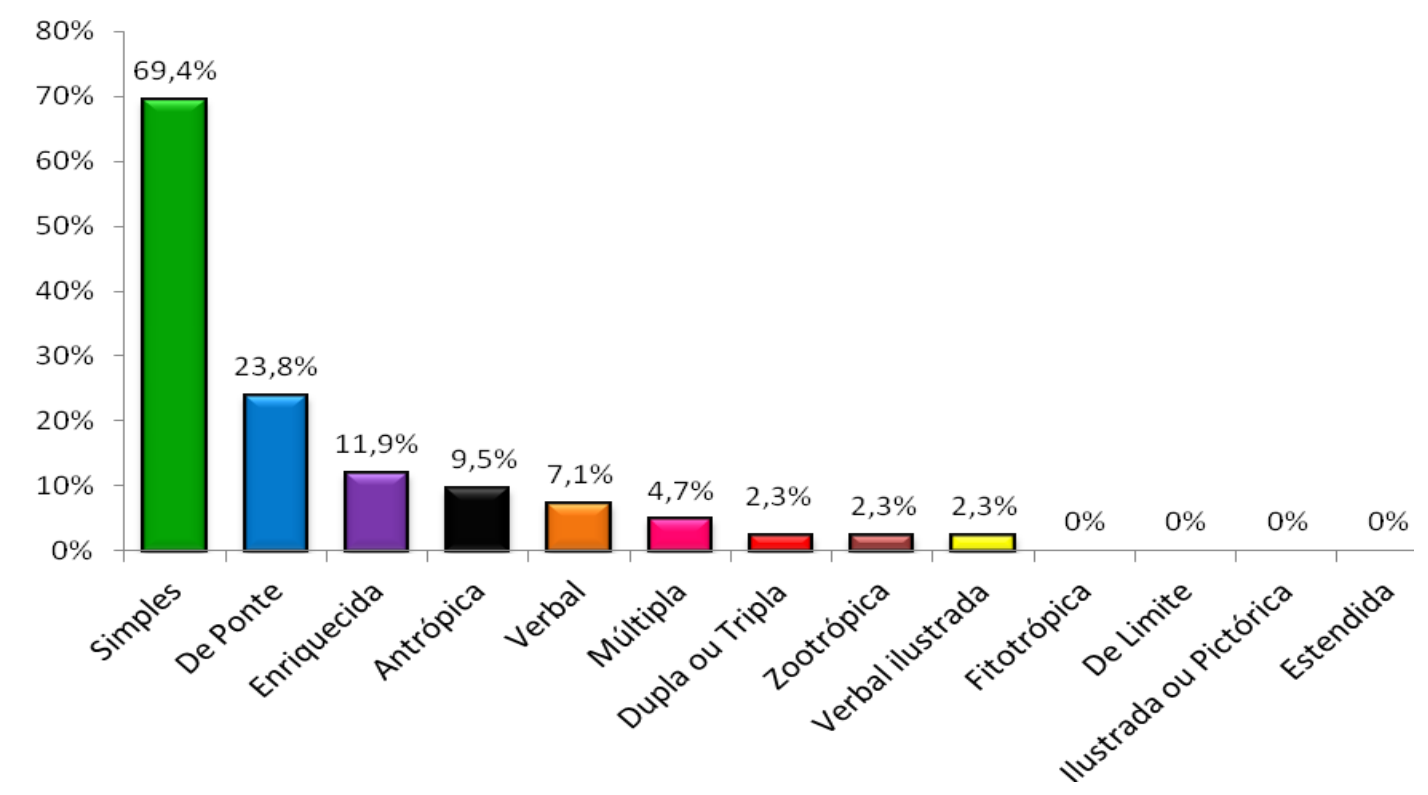

Fonte: KALAMAR, MACHADO, 2014.

As analogias aparecem mais simples para conteúdos de mais fácil entendimento e mais funcionais para conteúdos mais abstratos. E mesmo a genética sendo um conteúdo consideravelmente difícil, à analogia que obteve maior índice foi a classificada como simples, com $69,4 \%$. Talvez esse fato tenha ocorrido por se tratar de uma analogia similar a uma metáfora, o que não era esperado, já que a disciplina exige maior abstração para ser compreendida. Para Justi e Monteiro (2000), analogias simples podem ser consideradas modelos de ensino mais fracos, entretanto, depende da natureza do alvo e dos objetivos almejados, uma analogia simples pode ser eficaz e facilmente compreendida pelos alunos. Porem o que nota-se é que tal analogia foi utilizada em certos assuntos menos complexos como pode ser visualizada no livro de Mendonça e Laurence (2010, p. 182): "O genoma é como um registro autobibliografico, escrito na linguagem dos genes".

A segunda analogia mais frequente foi à de ponte, com $23,8 \%$. Esta analogia relaciona o conceito alvo com algum fato ou conceito do cotidiano dos alunos, sendo 
aqui representada pelo livro de César, Sezar e Caldini (2010, p.81): “É comum, nesse contexto, comparar-se os genes ás receitas contidas num livro de culinária, isto é, instruções para se fabricar algo, ou para fazer algo funcionar”.

Com 11,9\% está à analogia enriquecida, que faz o mapeamento explícito de algum atributo do domínio alvo ou análogo, específica às relações analógicas. Assim como citado no livro de Amabis e Martho (2010, p.126):

No processo de transcrição, as "letras" de uma sequência de DNA, que correspondem aos nucleotídeos de A, T, C e G, dão origem a uma sequencia de RNA, que possui outras "letras": A, U, C e G. Mas, ainda utilizando esta analogia, podemos dizer que o "idioma" continua o mesmo, pois DNA e RNA pertencem ao mesmo grupo de substâncias químicas, os ácidos nucleicos.

A analogia antrópica é utilizada quando se transmite uma distinção característica dos seres humanos e foi observada com 9,5\% de frequência. Como representada no livro de Lopes e Rosso (2010, p.344): “A analogia feita na musica refere-se as teclas brancas e pretas do piano, que vivem juntas em plena harmonia, o que seria de se esperar entre pessoas brancas e negras".

Com uma frequência de 7,1\% estão às analogias verbais, onde os alunos têm de imaginar a situação analógica, como presente no livro de Lopes e Rosso (2010, p.226): "Se todo o DNA do seu corpo fosse esticado em um único fio, teria comprimento para ir e voltar 8 mil vezes até a lua". Com 4,7\% estão às analogias Múltiplas, que colocam mais de um análogo para explicar o alvo, sendo revelada no livro de César; Sezar e Caldini (2010, p. 182):

Os plasmídeos são pequenas porções de DNA circular (em forma de anéis) encontrados no citoplasma das bactérias. Normalmente existem em cada célula dezenas a centenas de plasmídeos dispersos. Eles são usados como vetores, ou seja, como veículos para transferir ao interior das bactérias pequenos segmentos de DNA estranhos a elas.

Com 2,3\% estão às analogias dupla ou tripla, zootrópica e verbal ilustrada ou verbal pictórica. A analogia dupla ou tripla é utilizada quando dois ou mais conceitos alvos são explicados a dois ou mais conceitos análogos, citada livro de Amabis e Martho (2010, p. 62):

A segregação dos alelos de um gene em um organismo diploide é comparável a obtenção de "cara" ou "coroa" no lançamento de uma moeda. Suponha que o lançamento de uma moeda dourada represente a formação do gameta feminino, que o lançamento de uma moeda prateada represente a formação do gameta masculino, e que "cara" e "coroa" sejam os dois alelos de um gene, A e a. O resultado da fecundação é comparável a combinação das faces obtidas no lançamento simultâneo das duas moedas. 
A analogia zootrópica transmite um conceito de morfologia ou comportamento, atribuído aos animais. Um exemplo é a analogia observada no livro de Lopes e Rosso (2010, p.249). "O choro das crianças com essa síndrome assemelha-se ao miado de um gato, em consequências de alterações na laringe". A analogia verbal ilustrada ou verbal pictórica é apresentada de forma escrita, sendo reforçada por imagem ou figura (Figura $01)$.

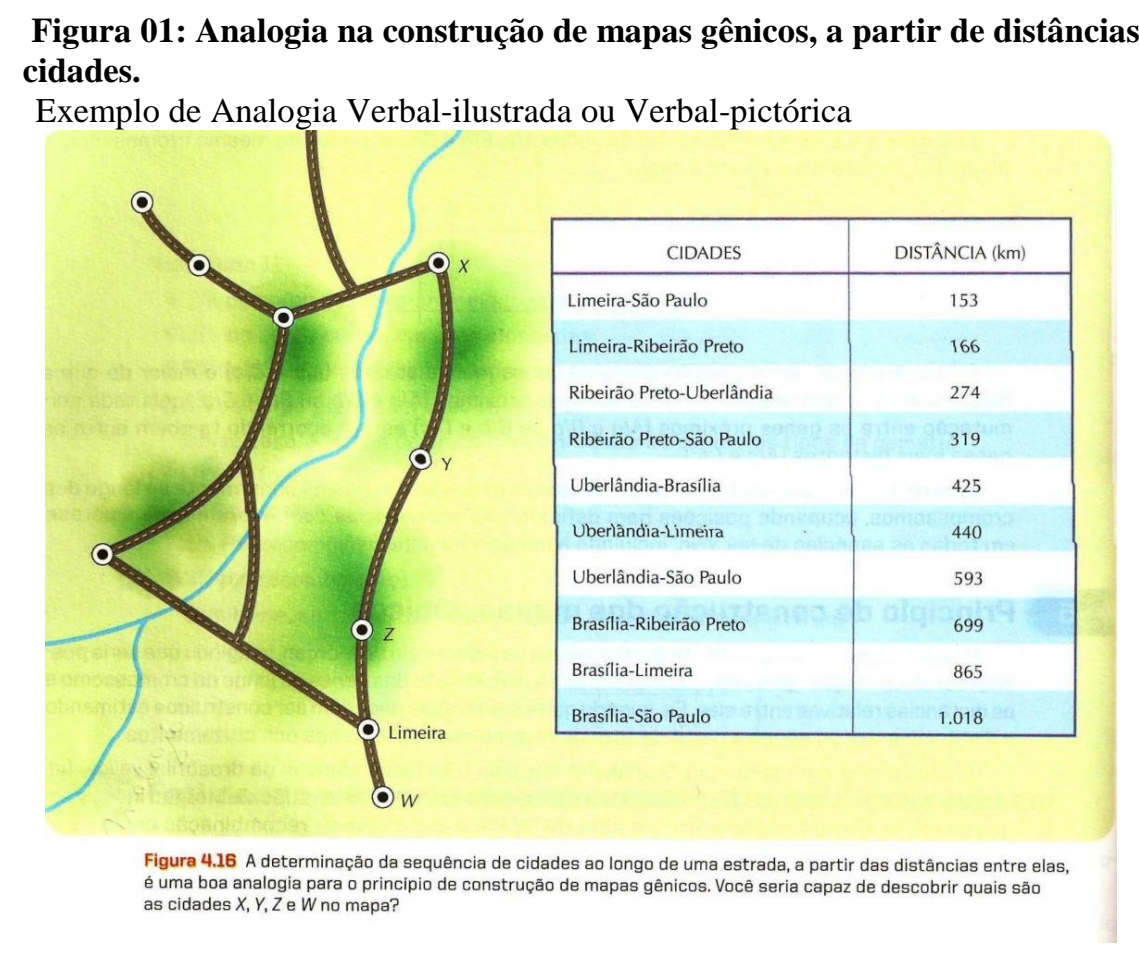

Fonte: AMABIS; MARTHO, 2010.

A figura 01 representa a construção de mapas gênicos a partir das distâncias entre os pontos das cidades existentes localizados ao longo de uma estrada. Uma boa alternativa para localizar o aluno ao conteúdo e fazer com que ele entenda o principio de como construir mapas gênicos.

O ensino de biologia é quase completamente imagem, o mundo é trazido para dentro da sala de aula através dela. O aluno não poderá entender apenas em palavras as moléculas de DNA, os genes, células, entre tantos outros temas. O uso de imagens como uma alternativa metodológica, melhora e muito a aprendizagem além de causar interesse e motivação (REICHMANN; SCHIMIN, 2008). Por isso, acredita-se que a utilização de novas tecnologias de ensino, sem dispensar o uso de imagens em aulas, 
seja um recurso a ser explorado no processo de ensino-aprendizagem (HECKLER; SARAIVA; OLIVEIRA, 2007).

Não foram observadas analogias fitotrópicas, de limite, estendida e a ilustrada ou pictórica, o que revela que estas analogias dificilmente são utilizadas. Porem Silva e Martins (2010) sugerem a utilização de analogias mais estruturais para a visualização de conceitos mais abstratos e um bom modelo seria as apresentadas na forma estendida, pois podem ser mais eficientes em um livro didático, possibilitando ao aluno a compreensão do conteúdo, já que apresenta todos os passos no próprio livro, sem a necessidade da intervenção do professor. Caso isso não aconteça, o professor deve estar preparado para complementá-la ou enriquecê-la em sala de aula.

Constatou-se que algumas analogias são muito comuns no ensino de genética, podendo ser consideradas clássicas no ensino de biologia (Tabela 07).

(Continua)

Tabela 7- Analogias comuns no ensino de genética encontradas repetidas em diferentes livros, por diversos autores.

\begin{tabular}{|c|c|c|}
\hline ANALOGIA & $\begin{array}{l}\text { NÚMERO DE } \\
\text { VEZES QUE } \\
\text { FOI CITADA } \\
\text { EM CADA } \\
\text { LIVRO }\end{array}$ & $\begin{array}{l}\text { LIVROS ONDE FOI } \\
\text { ENCONTRADA }\end{array}$ \\
\hline $\begin{array}{l}\text { Como a inativação ocorre ao } \\
\text { acaso, podendo ser inativado } \\
\text { tanto no cromossomo X } \\
\text { materno quanto no } \\
\text { cromossomo X paterno, o } \\
\text { corpo de uma fêmea de } \\
\text { mamífero é comparável a } \\
\text { um "mosaico". }\end{array}$ & 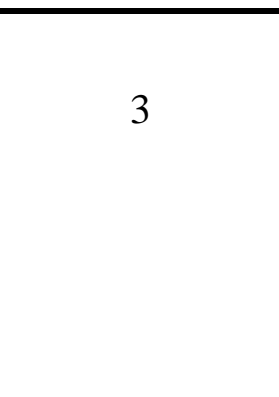 & $\begin{array}{l}\text { Amabis e Martho, } 2010 . \\
\text { Linhares e Gewandsznajder, } 2010 . \\
\text { Santos; Aguilar e Oliveira, } 2010 .\end{array}$ \\
\hline $\begin{array}{l}\text { As endonucleases de } \\
\text { restrição são enzimas } \\
\text { bacterianas que atuam como } \\
\text { "tesouras moleculares". }\end{array}$ & 4 & $\begin{array}{l}\text { Amabis e Martho, } 2010 . \\
\text { Lopes e Rosso, } 2010 . \\
\text { Linhares e Gewandsznajder, } \\
2010 . \\
\text { César; Sezar e Caldini, } 2010 .\end{array}$ \\
\hline $\begin{array}{l}\text { O DNA é como um livro de } \\
\text { receitas. }\end{array}$ & 2 & $\begin{array}{l}\text { Lopes e Rosso, } 2010 . \\
\text { César; Sezar e Caldini, } 2010 .\end{array}$ \\
\hline $\begin{array}{l}\text { O resultado é uma imagem } \\
\text { fotográfica semelhante a um } \\
\text { código de barras. }\end{array}$ & 3 & $\begin{array}{c}\text { Lopes e Rosso, } 2010 . \\
\text { Linhares e Gewandsznajder, } 2010 .\end{array}$ \\
\hline
\end{tabular}




\begin{tabular}{l|c|c}
\hline & & César; Sezar e Caldini, 2010. \\
\hline $\begin{array}{l}\text { É como se o DNA fosse uma } \\
\text { "impressão digital" da } \\
\text { pessoa. }\end{array}$ & 3 & Mendonça e Laurence, 2010. \\
& & $\begin{array}{c}\text { Linhares e Gewandsznajder, } 2010 . \\
\text { César; Sezar e Caldini, 2010. }\end{array}$ \\
\hline
\end{tabular}

Justi e Monteiro (2000) salientam que os autores dos livros didáticos acham essas analogias muito úteis para facilitar a compreensão dos conceitos e dessa forma, não elaboram novas analogias e seguem uma tradição ao longo da construção dos livros.

Certo número de analogias foi maior em determinados assuntos específicos dentro do tema Genética, a Tabela 8 demonstra os capítulos que apresentaram maiores números de analogias em cada livro.

Tabela 8- Relação das Analogias citadas por assunto.

\begin{tabular}{|c|c|c|}
\hline $\begin{array}{l}\text { LIVROS ONDE } \\
\text { FOI } \\
\text { ENCONTRADA }\end{array}$ & $\begin{array}{l}\text { NÚMERO DE } \\
\text { ANALOGIAS } \\
\text { ENCONTRADAS }\end{array}$ & $\begin{array}{l}\text { TÍTULO DO CAPÍTULO } \\
\text { (Conteúdo) }\end{array}$ \\
\hline $\begin{array}{l}\text { Amabis e Martho, } \\
2010 .\end{array}$ & 4 & $\begin{array}{l}\text { Aplicações do conhecimento genético. } \\
\text { (Utilização da genética através de } \\
\text { técnicas para o melhoramento da } \\
\text { qualidade de vida). }\end{array}$ \\
\hline $\begin{array}{l}\text { Lopes e Rosso, } \\
2010 .\end{array}$ & 4 & $\begin{array}{l}\text { A genética e os genes. (Estudo da } \\
\text { hereditariedade e da variação dos } \\
\text { organismos). }\end{array}$ \\
\hline $\begin{array}{l}\text { Mendonça } \\
\text { Laurence, } 2010 .\end{array}$ & 3 & $\begin{array}{l}\text { Biologia molecular do gene: Síntese } \\
\text { proteica e engenharia genética. (O que } \\
\text { são os genes, como funcionam e como } \\
\text { tal fenômeno ocorre no interior das } \\
\text { células). }\end{array}$ \\
\hline $\begin{array}{l}\text { Linhares } \\
\text { Gewandsznajder, } \\
2010 .\end{array}$ & 5 & $\begin{array}{l}\text { A Tecnologia do DNA. (Conjunto de } \\
\text { técnicas que permite identificar, isolar e } \\
\text { multiplicar genes de quaisquer } \\
\text { organismos). }\end{array}$ \\
\hline $\begin{array}{l}\text { César; Sezar } \\
\text { Caldini, } 2010 .\end{array}$ & 6 & $\begin{array}{l}\text { Biotecnologia. (Manipulação genética } \\
\text { envolvendo organismos). }\end{array}$ \\
\hline $\begin{array}{l}\text { Santos; Aguilar } \\
\text { Oliveira, } 2010 .\end{array}$ & 2 & $\begin{array}{l}\text { Primeiras ideias sobre } \text { genética. } \\
\text { (Introdução ao tema genética). }\end{array}$ \\
\hline
\end{tabular}

O número mais elevado de analogias foi encontrado no conteúdo de biotecnologia, acompanhado de tecnologia do DNA. Sendo assim, determinados temas 
necessitam de um maior numero de analogias, já que tratam de técnicas de manipulação genética envolvendo organismos.

Todas as analogias analisadas que foram citadas nos livros didáticos são familiares aos alunos, já que ao ler o texto estes conseguem compreender o assunto em questão. Isso demonstra que, no intuito de abordar de forma mais clara um conceito para o leitor, os autores de livros didáticos fazem uso de analogias com assuntos que são mais familiares que o conhecimento científico, o que auxilia na aprendizagem, pois utilizam referências do cotidiano do aluno e com uma linguagem mais acessível (HOFMANN; SHEID, 2007).

No entanto devemos ser cautelosos com algumas analogias, uma vez que podem não esclarecer o conteúdo e utilizar um análogo desconhecido ou pouco familiar aos estudantes dificultando desse modo o processo de ensino-aprendizagem. Caso o aluno não compreenda o recurso utilizado e tendo o livro como sua principal fonte de informações, analogias mal expressadas podem contribuir para a formação de conceitos equivocados (SILVA; MARTINS, 2010).

Zambon e Terrazzan (2013) defendem as analogias como estratégia alternativa trazida pelo professor ou livro didático, e a produção de analogias pelos próprios alunos e relata um estudo realizado com 30 meninos de 14 anos de idade, onde em um momento da aula, um dos alunos gerou uma analogia para explicar a conservação da corrente em um circuito elétrico, e nas aulas seguintes, a analogia foi explorada pela turma. Pelo estudo realizado, o autor concluiu que o processo de gerar e explorar analogias são uma importante alternativa para a promoção de autonomia e autoestima dos estudantes.

De fato a analogia permite o professor explorar o conteúdo, sendo vista como fator determinante quando existe a dificuldade de se compreenderem os conceitos e dessa forma o raciocínio analógico parece ser a fonte da compreensão dos estudantes em relação aos conceitos teóricos, sendo entendida por alunos e professores como eficaz, pois promove o entendimento dos conceitos (BOZELLI; NARDI, 2009). Porém de acordo com Nunes; Ferraz e Justina (2005), embora as analogias sejam constantemente utilizadas no processo de ensino de ciências, pouco se tem investigado sobre o tema no Brasil, mostrando uma carência de pesquisas na área. 


\section{CONCLUSÃO}

Por meio deste trabalho constatamos a presença de analogias nos livros didáticos de biologia e destacamos o quanto estas auxiliam no ensino de genética. Introduzir analogias na disciplina de biologia como ferramenta didática no processo de ensino pode auxiliar no aprendizado por trazer o aluno para a sua realidade, utilizando uma linguagem mais simples e deixando o conteúdo com mais fácil compreensão.

Mas vale lembrar que estas analogias devem ser bem empregadas, caso contrário, podem confundir o aluno e atrapalhar o aprendizado a partir de conceitos equivocados.

Notamos que as analogias do tipo simples são as que mais se destacam nos livros didáticos. Estas são analogias muito utilizadas em nosso dia a dia, as quais não seriam tão recomendáveis no tema genética, que trata de assuntos complexos, necessitando assim de analogias mais explicativas ou mais minuciosas, no entanto, conforme foi constatado no presente estudo, estas ainda são pouco utilizadas em livros didáticos.

Por fim, ressaltamos que o uso de analogias contribui para o aprendizado de biologia, sendo significativo o seu uso na construção e melhor compreensão dos conceitos, pois consiste em um método aliado para atingir os objetivos educacionais.

\section{REFERÊNCIAS}

AGAMME, A.L.D.A. O lúdico no ensino de genética: a utilização de um jogo para entender a meiose. Monografia apresentada ao Centro de Ciências Biológicas e da Saúde, da Universidade Presbiteriana Mackenzie - São Paulo, 2010.

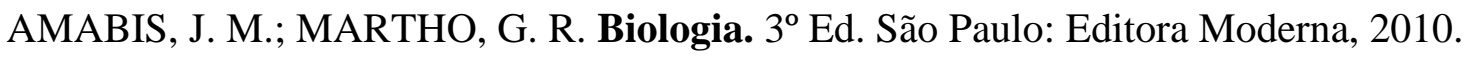

BIZZO, N. Biologia. $1^{\circ}$ Ed. São Paulo: Editora Ática, 2010.

BOZELLI, F.C; NARDI, R. Ensino de física, analogias e a dinâmica do contexto interativo discursivo em sala de aula. Ensino de ciências e matemática - Unesp Universidade Estadual Paulista SP, 2009.

DUARTE, M. C. Analogias na educação em ciências contributos e desafios.

Investigações em Ensino de Ciências V10(1), pp. 7-29 - Instituto de Educação e Psicologia Universidade do Minho Braga, Portugal, 2005. 
FABIÃO, L.S; DUARTE, M.C. Dificuldades de produção e exploração de analogias: um estudo no tema equilíbrio químico com alunos/futuros professores de ciências.

Revista Electrónica de Enseñanza de las Ciencias Vol. $4 N^{o} 1$ Portugal, 2005.

FERRAZ, D.F; TERRAZZAN, E.A. O uso espontâneo de analogias por professores de biologia: Observações da prática pedagógica. ENSAI O - Pesquisa em Educação em Ciências Volume 04 / Número 2 - Minas Gerais, 2002.

FIGUEROA, A.M.S; NAGEM, R.L; CARVALHO, E.M. Metodologia de ensino com analogias: um estudo sobre a classificação dos animais. Revista Iberoamericana de Educación Nov, 2003.

GIRALDI, P. M. Linguagem em textos didáticos de Citologia: Investigando o uso de Analogias. Dissertação de Mestrado em Educação Científica e Tecnológica Universidade Federal de Santa Catarina, Florianópolis, 2005.

GOLDBACH, T; EL-HANI, C.N. Entre Receitas, Programas e Códigos: Metáforas e Ideias Sobre Genes na Divulgação Científica e no Contexto Escolar. ALEXANDRIA Revista de Educação em Ciência e Tecnologia, v.1, n.1, p. 153-189, mar. 2008.

HECKLER, V. SARAIVA, M.F.O; OLIVEIRA, K.S.F. Uso de simuladores, imagens e animações como ferramentas auxiliares no ensino/aprendizagem de óptica. Revista Brasileira de Ensino de Física, v. 29, n. 2, p. 267-273 Rio Grande do Sul, 2007.

HOFFMANN, M. B.; SCHEID, N. M. J. Analogias presentes em livros didáticos de Biologia. $2^{\mathbf{o}}$ Encontro Regional Sul de Ensino de Biologia - $3^{\text {a Jornada de }}$ Licenciatura em Ciências Biológicas da UFSC, Florianópolis, 2006.

HOFFMANN, M. B.; SCHEID, N. M. J. Analogias como ferramenta didática no Ensino de Biologia. Ensaio Pesquisa em Educação em Ciências - Universidade Federal de Minas Gerais, 2007.

HOFFMANN, M. B. Potencialidades do uso de analogias históricas em aulas de Ciências e Biologia. Universidade Federal de Santa Catarina, 2012.

JUNIOR, W. E. F. Analogias em livros didáticos de química: um estudo das obras aprovadas pelo Plano Nacional do Livro Didático Para o Ensino Médio 2007. Ciências \& Cognição Vol 14 (1): 121-143 - Universidade Federal de Rondônia (UNIR), 2009.

JÚNIOR, C. S.; SASSON, S.; JÚNIOR, N. C.; Biologia. $10^{\circ}$ Ed. São Paulo: Editora Saraiva, 2010.

JUSTI, R. S.; MONTEIRO, I. G. Analogias em livros didáticos de química brasileiros destinados ao Ensino Médio. Investigações em Ensino de Ciências V5 (2), pp. 67-91Universidade Federal de Minas Gerais, Belo Horizonte, 2000.

JUSTI, R.; MENDONÇA, P. C. C. Usando analogias com função criativa: uma nova estratégia para o ensino de química. Departamento de Química \& Programa de Pósgraduação em Educação - Universidade Federal de Minas Gerais, 2003. 
LINHARES, S.; GEWANDSZNAJDER, F. Biologia. $1^{\circ}$ Ed. São Paulo: Editora Ática, 2010 .

LOPES, S.; ROSSO, S. Bio. $1^{\circ}$ Ed. São Paulo: Editora Saraiva, 2010.

MAESTRELLI, S.R.P; FERRARI, N. O Óleo de Lorenzo: O uso do cinema para contextualizar o ensino de genética e discutir a construção do conhecimento científico. Genética na Escola, 2006.

MARTINS, R. T. M. C.; BARREIRA, S. Sugestão de uso de uma Analogia diferente para explicar a atividade enzimática em Biologia do Ensino Médio: O MODELO DA AMIGA - CUPIDO. IV congresso de pesquisa e inovação da rede Norte e Nordeste de Educação Tecnológica- Instituto Federal de Educação, Ciência e Tecnologia, Belém, 2009.

MELO, J. R; CARMO, E.M. Investigações sobre o ensino de genética e biologia molecular no ensino médio brasileiro: Reflexões sobre as publicações científicas. Ciência \& Educação, v. 15, n. 3, p. 593-611 Bahia, 2009.

MENDONÇA, V.; LAURENCE, J. Biologia. $1^{\circ}$ Ed. São Paulo: Editora Nova Geração, 2010.

NETO, J. M.; FRACALANZA, H. O Livro Didático de ciências: Problemas e Soluções. Ciência \& Educação, v. 9, n. 2, p. 147-157 - Congresso Brasileiro de Qualidade na Educação, Brasília, 2003.

NUNES, R.R; FERRAZ, D.F; JUSTINA, L.A.D. Estudos relativos a analogias no ensino de ciências. Universidade Federal do Mato Grosso do Sul, 2005.

OLIVEIRA, H. R. Argumentação no ensino de ciências: O uso de analogias como recurso para a construção do conhecimento. Dissertação apresentada ao Programa de Pós-Graduação em Educação da Universidade Federal de Juiz de Fora, 2012.

PEDROSO. C.V; AMORIM. M. A. L; Uso de uma atividade didática baseada em analogia para o ensino de genética: o que há de comum entre dois prédios iguais e cromossomos homólogos? X Salão de Iniciação Científica - PUCRS, 2009.

PEZZI, A.; GOWDAK, D. O.; MATTOS, N. S. Biologia. $1^{\circ}$ Ed. São Paulo: editora FTD, 2010.

REICHMANN, D. R. X. T; SCHIMIN, E. S. Imagens: Contribuição para o ensinoaprendizagem em Biologia. UNICENTRO- Guarapuava, 2008.

RIGOLON, R. G. O conceito e o uso de analogias como recurso didático por licenciados de biologia. Dissertação de obtenção do título de Mestre em Educação Universidade Estadual de Maringá, 2006.

SANTOS, F. S.; AGUILAR, J. B. V.; OLIVEIRA, M. M. A. Biologia Ser Protagonista. $1^{\circ}$ Ed. São Paulo: Editora SM, 2010. 
SANTOS, S. C. S.; TERÁN, A. F.; FORSBERGUE, M. C. S. Analogias em Livros Didáticos de Biologia no Ensino de Zoologia. Investigações em Ensino de Ciências V15(3), pp. 591-603 - Universidade do Estado do Amazonas, Manaus, 2011.

SANTOS, A. C. F; NUNES, L. N. Utilizando analogias para a visualização de equipotenciais com uma planilha de dados. Revista Brasileira de Ensino de Física, v. 35, n. 2, 2401. Rio de Janeiro, 2013.

SILVA, A. M. O uso de analogias no ensino de Ciências. Monografia apresentada à obtenção do título de especialista em Ensino de Ciências - Universidade Federal de Minas Gerais, Belo Horizonte, 2007.

SILVA, C. A. S; MARTINS, M. I. Analogias e metáforas nos livros didáticos de física. Pontifícia Universidade Católica de Minas Gerais Cad. Bras. Ens. Fís., v. 27, n. 2: p. 255-287, ago. Belo Horizonte, 2010.

SOARES, F. C.; FERRAZ, D. F.; JUSTINA, L. A. D. O uso de Analogias no Ensino de Biologia: Construção e Implementação de Estratégia Didática seguindo o modelo TWA (Teaching With Analogies). Revista Brasileira de Biociências, Porto Alegre, 2008.

TEMP, D. S. Facilitando a aprendizagem de Genética: Uso de um modelo didático e analise dos recursos presentes em livros de Biologia. Dissertação de Mestrado de Educação em Ciências - Universidade Federal de Santa Maria UFSM, RS, 2011.

TERRAZAN, E. A. et al. O uso de analogias em coleções didáticas de Física, Química e Biologia segundo o "estilo" dos autores e a "natureza" do tópico conceitual. IV encontro nacional de pesquisa em educação em ciências, Santa Maria, RS 2005.

TERRAZZAN, E. A. et al. Estudo das analogias utilizadas em coleções didáticas de física, química e biologia. ENSEÑANZA DE LAS CIENCIAS Universidade Federal de Santa Maria, 2005.

ZAMBON, L. B.; PICCINI, P. P.; TERRAZAN, E. A. Comparando a utilização de analogias em Livros Didáticos para Educação em Ciências. Encontro Nacional de Pesquisa e Educação em Ciências - Florianópolis, 2009.

ZAMBON, B.Z; TERRAZZAN, E. A. Analogias produzidas por alunos do ensino médio em aulas de física, Revista Brasileira de Ensino de Física, v. 35, n. 1, 1505 Universidade Federal de Santa Maria RS, 2013. 